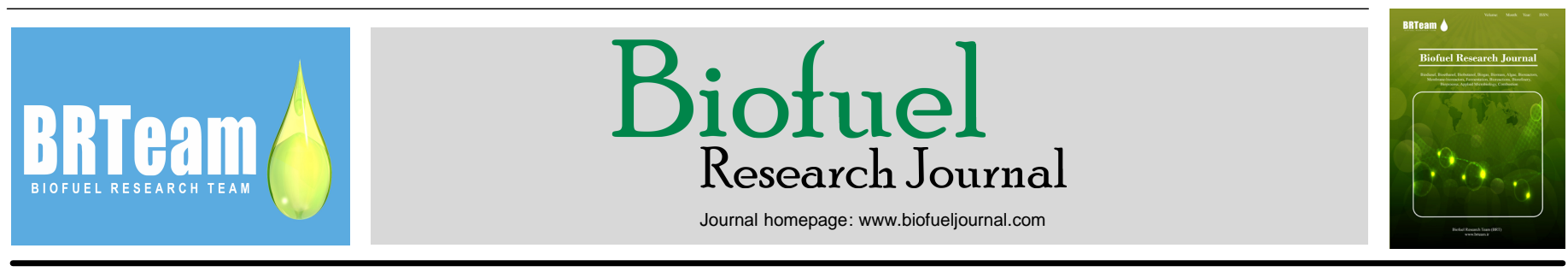

Original Research Paper

\title{
Fungal biomass and ethanol from lignocelluloses using Rhizopus pellets under simultaneous saccharification, filtration, and fermentation (SSFF)
}

\author{
Somayeh FazeliNejad, Jorge A. Ferreira*, Tomas Brandberg, Patrik R. Lennartsson, Mohammad J. Taherzadeh
}

Swedish Centre for Resource Recovery, University of Borås, SE 501 90, Borås, Sweden.

\section{HIGHLIGHTS}

$>$ Economically viable production of $2^{\text {nd }}$ generation

bioethanol cannot rely on a single product.

$>$ SSFF can be used for production of ethanol and

biomass from wheat straw.

$>$ Glucose present in the feed controlled the

assimilation of xylose and acetic acid.

$>$ The fungal growth rate was found not to be

influenced by the feed composition.

$>$ Rhizopus biomass yields of up $0.34 \mathrm{~g} / \mathrm{g}$ and ethanol

yields of $0.40 \mathrm{~g} / \mathrm{g}$ were obtained.

\section{GRAPHICAL ABSTRACT}

Acid-pretreated wheat slurry

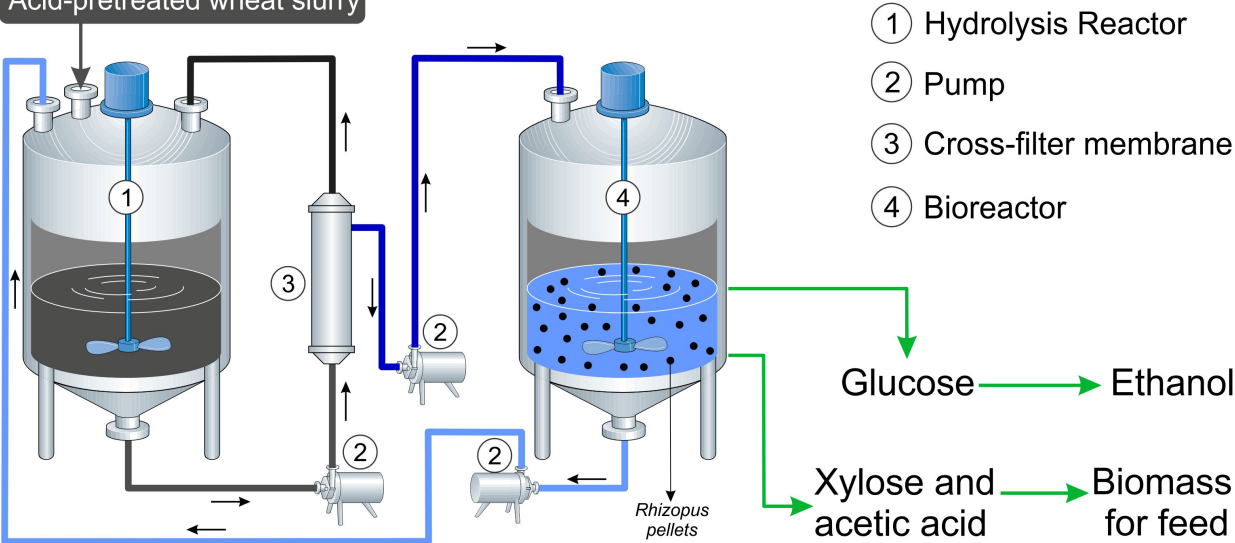

\section{ARTICLE INFO}

\section{Article history:}

Received 23 October 2015

Received in revised form 5 January 2016

Accepted 6 January 2016

Available online 1 March 2016

\section{Keywords:}

Cellulosic ethanol

Animal feed

Rhizopus sp.

SSFF

Wheat straw

\begin{abstract}
The economic viability of the $2^{\text {nd }}$ generation bioethanol production process cannot rely on a single product but on a biorefinery built around it. In this work, ethanol and fungal biomass (animal feed) were produced from acid-pretreated wheat straw slurry under an innovative simultaneous saccharification, fermentation, and filtration (SSFF) strategy. A membrane unit separated the solids from the liquid and the latter was converted to biomass or to both biomass and ethanol in the fermentation reactor containing Rhizopus sp. pellets. Biomass yields of up to $0.34 \mathrm{~g} / \mathrm{g}$ based on the consumed monomeric sugars and acetic acid were achieved. A surplus of glucose in the feed resulted in ethanol production and reduced the biomass yield, whereas limiting glucose concentrations resulted in higher consumption of xylose and acetic acid. The specific growth rate, in the range of $0.013-0.015 / \mathrm{h}$, did not appear to be influenced by the composition of the carbon source. Under anaerobic conditions, an ethanol yield of $0.40 \mathrm{~g} / \mathrm{g}$ was obtained. The present strategy benefits from the easier separation of the biomass from the medium and the fungus ability to assimilate carbon residuals in comparison with when yeast is used. More specifically, it allows in-situ separation of insoluble solids leading to the production of pure fungal biomass as a value-added product.
\end{abstract}

(c) 2016 BRTeam. All rights reserved.

* Corresponding author at: Tel.: +46-33-4354638

E-mail address: Jorge.Ferreira@hb.se

Please cite this article as: FazeliNejad S., Ferreira J.A., Brandberg T., Lennartsson P.R., Taherzadeh M.J. Fungal protein and ethanol from lignocelluloses using Rhizopus pellets under simultaneous saccharification, filtration and fermentation (SSFF). Biofuel Research Journal 9 (2016) $372-378$. DOI: $10.18331 / \mathrm{BRJ} 2016.3 .1 .7$ 


\section{Introduction}

Nowadays, the production of $1^{\text {st }}$ generation bioethanol from agricultural sugar- or starch-rich crops, as a replacement to gasoline, is well established at commercial scale. The leading ethanol-producing countries, USA and Brazil, use corn and sugarcane as main feedstocks, respectively (RFA, 2014). However, ethical issues related to the use of sugar- or starch-rich feedstocks for fuel production instead of being directed to human consumption have put pressure on finding alternative feedstocks (Cherubini, 2010).

The production of ethanol from lignocellulosic materials has been considered for several decades (Leonard and Hajny, 1945). Nevertheless, due to their recalcitrant structure, a feasible commercial facility producing the socalled $2^{\text {nd }}$ generation bioethanol is presently inexistent and is only limited to some pilot plants (Pandey et al., 2015). Constraints include the cost-intensive pretreatment needed to open up the lignocellulosic structure, the cost of enzymes needed in the post-pretreatment stage, the lack of robust microorganisms that can cope with inhibitors, and robust cultivation strategies that can meet all requirements for feasible $2^{\text {nd }}$ generation bioethanol prodution (Ishola, 2014). Another conclusion drawn by the intensive studies conducted over years is that a facility using lignocelluloses as feedstock cannot rely on a single product (i.e., ethanol) for achieving an economically-viable operation (Pandey et al., 2015).

The most commonly used strategies for production of ethanol include simultaneous saccharification and fermentation (SSF) and separate hydrolysis and fermentation (SHF). Running a SSF instead of a SHF circumvents the product inhibition of cellulase enzymes due to glucose accumulation (Olofsson et al., 2008). However, SSF disadvantageously requires the use of new microorganisms at each batch since it is difficult to separate them from the medium (Wingren et al., 2003). Therefore, a new cultivation strategy, i.e., simultaneous saccharification, filtration, and fermentation (SSFF) was developed by Ishola et al. (2013). This new concept consists of a membrane unit (cross-flow membrane) connecting a hydrolysis reactor to a fermentation reactor. The enzyme-slurry mixture from the hydrolysis reactor is filtered and the sugar-rich permeate is continuously supplied to the fermentation reactor while the residues are returned to the hydrolysis reactor. The fermented medium in the fermentation reactor is also pumped back to the hydrolysis reactor for volume balance (Fig. 1).

\section{Acid-pretreated wheat slurry}

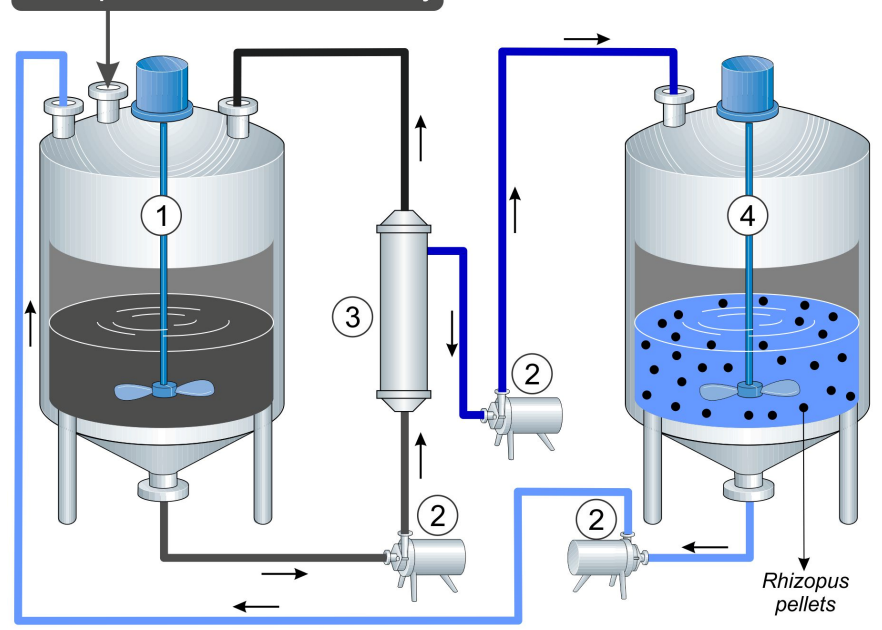

(1) Hydrolysis Reactor (2) Pump
(3) Cross-filter membrane

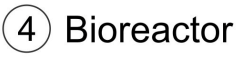

Fig.1. Schematic representation of SSFF for aerobic biomass (Rhizopus sp.) production.

Therefore, SSFF combines the advantages of both SSF and SHF by simultaneously solving their limitations, i.e., both hydrolysis and fermentation can be carried out at optimal conditions, the end-product inhibition is avoided, and there is also the possibility to reuse the fermenting cells. The fact that the fermenting cells is free from solid substrates (i.e., lignocellulosic materials) in the fermentation reactor under the SSFF, opens up the opportunity for the production of a second value-added product (i.e., biomass as animal feed) from the residual glucose, pentose sugars (such as xylose), and other components (such as acetic acid) contained in the pretreated wheat straw slurry. This would be a similar situation as exists for the $1^{\text {st }}$ generation bioethanol plants from starch grains where both ethanol and animal feed products are generated (Kim et al., 2008).

Edible filamentous fungi have been previously used for production of protein-rich biomass (animal feed) from various types of substrates (Ferreira et al., 2013). For instance, tempe-isolated zygomycete Rhizopus sp. has been found to cope with inhibitors contained in lignocellulosic hydrolysates (FazeliNejad et al., 2013). Moreover, these microorganisms form pellets, and therefore, could be easily separated from the medium (Nyman et al., 2013). They also consume pentose sugars contrary to baker's yeast Saccharomyces cerevisiae (Wikandari et al., 2012). These attributes mark these fungi as appropriate candidates for application in the SSFF. Among the different lignocellulosic materials, wheat straw is an economic agricultural by-product available at huge amounts with potentials for production of ethanol in view of its cellulose $(33 \%)$ and hemicellulose (33\%) dry weight contents (Canilha et al., 2006). It is worth quoting that various studies have been carried out on the pretreatment and hydrolysis of wheat straw (Talebnia et al., 2010; Baboukani et al., 2012; Peng et al., 2012).

In the present work, SSFF was used for ethanol production from glucose using $S$. cerevisiae as well as biomass (animal feed) production from residual carbon sources using Rhizopus sp. in pellet form. The effects of the enzyme addition to the hydrolysis reactor, temperature in the hydrolysis and fermentation reactors, and aeration for assimilation of carbon sources in the filtered permeate for production of biomass (animal feed) were investigated. This is the first work reporting the use of SSFF with filamentous fungi Rhizopus sp. for the production of two value-added products, i.e., bioethanol and animal feed from lignocellulosic materials.

\section{Materials and methods}

\subsection{Microorganisms}

Rhizopus sp. CCUG 61147 (Culture Collection University of Gothenburg, Sweden) isolated from Indonesian leaves traditionally used for preparation of tempe, was used in this work. The strain was identified as RM4 in a previous publication (Wikandari et al., 2012). The fungus was kept in Potato Dextrose Agar (PDA) plates and its incubation and preparation for inoculation were carried out according to FazeliNejad et al. (2013). A strain of S. cerevisiae, Ethanol Red, kindly provided by Fermentis (France) in dry form was also used.

\subsection{Pretreated wheat straw slurry}

Slurry of wheat straw delivered by SEKAB E-Technology (Örnsköldsvik, Sweden) was produced by continuous treatment of wheat straw at 22 bar for 5-7 min. The resulting slurry, a liquid fraction with fine particles, had $14.6 \%$ suspended solids (SS) and $23.8 \%$ total solids (TS). The liquid had a $\mathrm{pH}$ value of 2.0 and contained (in $\mathrm{g} / \mathrm{L}$ ): glucose, 7.2; xylose, 22.1; galactose, 2.3; arabinose, 4.6; acetic acid, 5.9; 5-hydroxy methyl-furfural (HMF), 2.1; and furfural, 4.2. The solid fraction contained $34.7 \%(\mathrm{w} / \mathrm{w})$ glucan and $4.6 \%(\mathrm{w} / \mathrm{w})$ xylan.

\subsection{Enzyme cocktail}

Cellic ${ }^{\circledR}$ CTec2, kindly provided by Novozymes (Denmark), was used in the experiments for enzymatic treatment. The product had an activity of 168 filter paper units (FPU)/mL.

\subsection{Inoculant preparation and cultivations in shake-flasks}

A complex medium containing (in $\mathrm{g} / \mathrm{L}$ ): xylose, 20; potato extract, 4 ; soybean peptone, 6 ; and $\mathrm{CaCO}_{3}, 6$ was used for preparation of Rhizopus sp. pellets as inoculant. The medium $(50 \mathrm{~mL})$ was transferred to $250 \mathrm{~mL}$ 
cotton-plugged Erlenmeyer flasks followed by sterilization in an autoclave at $121{ }^{\circ} \mathrm{C}$ for $20 \mathrm{~min}$. It should be noted that xylose was autoclaved separately. After mixing and inoculation with $1.0 \times 10^{5}$ spores $/ \mathrm{mL}$ of Rhizopus sp., the flasks were kept in a water-bath at $30^{\circ} \mathrm{C}$ and $150 \mathrm{rpm}$ for $72 \mathrm{~h}$. The produced Rhizopus sp. pellets were transferred to new cultivations to a cell concentration of $1.65 \pm 0.10 \mathrm{~g} / \mathrm{L}$ (dry weight $\pm 1 \mathrm{SD}$ ). The new cultivations were carried out in $250-\mathrm{mL}$ Erlenmeyer flasks containing $100 \mathrm{~mL}$ of the same medium which also consisted of (in g/L): $\left(\mathrm{NH}_{4}\right)_{2} \mathrm{SO}_{4}, 7.5 ; \mathrm{KH}_{2} \mathrm{PO}_{4}, 3.5$; $\mathrm{CaCl}_{2} 2 \mathrm{H}_{2} \mathrm{O}, 1 ; \mathrm{MgSO}_{4} 7 \mathrm{H}_{2} \mathrm{O}, 0.75$; and one of the following carbon sources namely acetic acid, 5.0; ethanol, 10; glucose, 10; lactic acid, 10; and xylose, 10. The cultivations were kept in a water-bath at $30{ }^{\circ} \mathrm{C}$ while being shaken at $150 \mathrm{rpm}$.

With similar preparation of the initial inoculant, $2.20 \pm 0.12 \mathrm{~g} / \mathrm{L}$ pellets (dry weight, $\pm 1 \mathrm{SD}$ ) were transferred to a new medium and cultivated as described above but a combination of the carbon sources at $3.5 \mathrm{~g} / \mathrm{L}$ was used. This experiment was carried out in duplicate.

Liquid samples were withdrawn and stored at $-20{ }^{\circ} \mathrm{C}$ for subsequent analysis. At the end of the cultivation, the pellets were harvested using a sieve, washed with distilled water, and dried in an oven at $70{ }^{\circ} \mathrm{C}$ to constant weight for $24 \mathrm{~h}$. The cultivations using single-carbon sources or their combination were performed in quadruplicate and duplicate, respectively.

\subsection{Cultivations under SSFF}

The SSFF as previously described by Ishola et al. (2013) was employed. The lignocellulosic feedstock was hydrolysed enzymatically in a separate vessel (hydrolysis reactor) and the resulting sugar-rich liquid was circulated through the fermentation reactor, where the fungal biomass production took place. The solid fraction was separated from the sugar-rich stream by a crossflow membrane. However, a cell retention system was not needed in this work since $5 \mathrm{~mm}$ spherical pellets of Rhizopus sp. were used and they maintained this morphology throughout the cultivations.

For the SSFF trials, pellets were prepared as described above and transferred to a $750 \mathrm{~mL}$ fermentor (Ant, Belach Bioteknik AB, Sweden) containing sterilized salt solution as described above and $0.1 \mathrm{~g} / \mathrm{L}$ antifoam. The transferred Rhizopus sp. pellets had an initial dry weight within the range $1.5-2.1 \mathrm{~g}$ and the volume was adjusted to a total volume of $500 \mathrm{~mL}$. Wheat straw slurry was transferred to a parallel hydrolysis reactor (Memma, Belach Bioteknik AB, Sweden) and diluted with deionized water to $5.0 \%$ SS to a total volume of $3.5 \mathrm{~L}$. The salt and antifoam content was the same as in the fermentation reactor. The cross-flow membrane unit was set up according to Ishola et al. (2013). After integration (Fig. 1), the flow of the filtrate through the fermentation bioreactor was $40 \mathrm{~mL} / \mathrm{h}$.

In a first experiment, the integration of the SSFF system was preceded by $24 \mathrm{~h}$ enzymatic decomposition by addition of $\mathrm{Cellic}^{\circledR} \mathrm{CTec} 2$, corresponding to $10 \mathrm{FPU} / \mathrm{g}$ SS. The $\mathrm{pH}$ was initially adjusted to 5.5 in both reactors and regulated to 5.5 in the fermentation reactor by on-line addition of $2.0 \mathrm{M}$ $\mathrm{NaOH}$. The temperature was kept at $50{ }^{\circ} \mathrm{C}$ in the hydrolysis reactor and $35{ }^{\circ} \mathrm{C}$ in the fermentation reactor. The stirring was $350 \mathrm{rpm}$ in the hydrolysis vessel and $100 \mathrm{rpm}$ in the fermentation bioreactor, which was aerated at $1 \mathrm{vvm}$ (volume of air per volume of liquid per minute). The experiment was carried out in duplicate where the integration phase lasted for $140 \mathrm{~h}$ and $168 \mathrm{~h}$. Samples were withdrawn directly from the tubes channeling medium in and out of the fermentation vessel. The final cell (biomass) content was analysed by weighing it after drying at $70{ }^{\circ} \mathrm{C}$ for $24 \mathrm{~h}$. The experiment was then repeated with the same parameters but with the following differences; no enzyme was added and the integration phase lasted for $72 \mathrm{~h}$. This was intended to investigate the impact of enzyme addition into the hydrolysis reactor.

In a similarly initiated experiment, the effect of aeration in the fermentation reactor was investigated by switching off the air supply after 72 h. Moreover, $10 \mathrm{FPU} / \mathrm{g}$ SS enzyme was simultaneously added into the hydrolysis reactor. This anaerobic fermentation phase lasted for $94 \mathrm{~h}$.

Another SSFF trial was also carried out where the temperature was adjusted to $35{ }^{\circ} \mathrm{C}$ in both reactors. Enzyme (10 FPU/g SS) and $15 \mathrm{~g}$ of dry baker's yeast were added to the hydrolysis reactor. The experiment was carried out in duplicate where the integration phase lasted for 96 and $120 \mathrm{~h}$.

In a different set-up, the similar cultivation as of above (i.e., $35^{\circ} \mathrm{C}, 10$ FPU/g SS, and $15 \mathrm{~g}$ dry yeast) was initially performed without any integration for $54 \mathrm{~h}$. The resulting fermented slurry was then distilled using a rotary evaporator (Labinett, Sweden) at $140{ }^{\circ} \mathrm{C}$ (oil bath), and $30 \mathrm{rpm}$ rotation speed at atmospheric pressure. The water content lost during distillation was re-adjusted by the addition of sterile ultrapure water. The resulting slurry, now without ethanol, was used for integration with the SSFF and aerobic production of Rhizopus sp. biomass as described above during 96 h.

\subsection{Analytical methods}

The measurements of glucose, metabolites, and inhibitors concentrations as well as spore counting were performed according to FazeliNejad et al. (2013). The SS was determined by filtration with Munktell filters, Grade $3(5-8 \mu \mathrm{m})$ while the TS were determined by drying the samples to a constant weight at $105{ }^{\circ} \mathrm{C}$ overnight. The solid fraction of the wheat straw slurry and the enzyme activity were analyzed according to the NREL protocols (Adney and Baker, 2008; Sluiter et al., 2011).

\section{Results and discussion}

\subsection{SSFF of wheat straw slurry with Rhizopus sp. pellets}

Production of additional products in a biorefinery concept has been proposed to improve the process economy of ethanol production from cellulosic raw materials (Wheals et al., 1999; Gnansounou and Dauriat, 2010). Animal feed in the form of Rhizopus sp. biomass has been suggested as a valuable co-product for ligno-ethanol in the present study. Implementing SSFF for aerobic production of Rhizopus sp. biomass entails the application of a cross-flow membrane to separate available sugars and other organic compounds from a pretreated lignocellulosic slurry (Fig. 1). The filtrate is supplied to an aerated fermentor, where carbon sources are consumed by Rhizopus sp. pellets in order to produce biomass (animal feed)

The pellet morphology is useful in order to prevent leakage of biomass when liquid is pumped back to the hydrolysis reactor. This reflux is necessary in order to maintain the liquid balance between the vessels and to prevent increasing the dry matter content of the slurry. Besides, the glucose concentration, which would increase as a result of enzymatic decomposition of cellulose and could inhibit the enzymes, can be controlled in this way.

On the other hand, the filtration of the slurry is in itself a very important operation since the solid fraction must not be mixed with the biomass, which would result in a downstream separation problem. In addition to biomass, the Rhizopus sp. used in this work is also a potential producer of ethanol (Wikandari et al., 2012).

The implementation of SSFF for production of ethanol and biomass includes the use of continuous cross-flow membrane as described earlier. The results obtained revealed that the filtration unit was used for up to 168 $\mathrm{h}$ without regeneration of the membrane and without any fouling. In a similar experiment, involving the slurry of pretreated spruce, the same operation was performed during $28 \mathrm{~d}$ without interruption, regeneration, or fouling (Ishola et al., 2013).

\subsection{Specific growth rate and biomass yield}

Various SSFF experiments with Rhizopus sp. production from wheat straw slurry were carried out in order to validate this concept. The main difference between the different trials was the composition of the substrate, notably its glucose content. Enzymatic decomposition of cellulose in the solid fraction prior to integration with SSFF (Fig. 2) produced a relatively high initial glucose concentration in contrast to a similar experiment without enzyme addition (Table 1 ).

The addition of baker's yeast to the hydrolysis vessel in a different experiment nearly eliminated the glucose in the inflow to the fermentation reactor. Furthermore, an experiment was carried out where the amount of glucose was reduced by the addition of baker's yeast and the produced ethanol was also removed by distillation. The resulting mix was used for Rhizopus sp. production by SSFF (Table 1 ). 

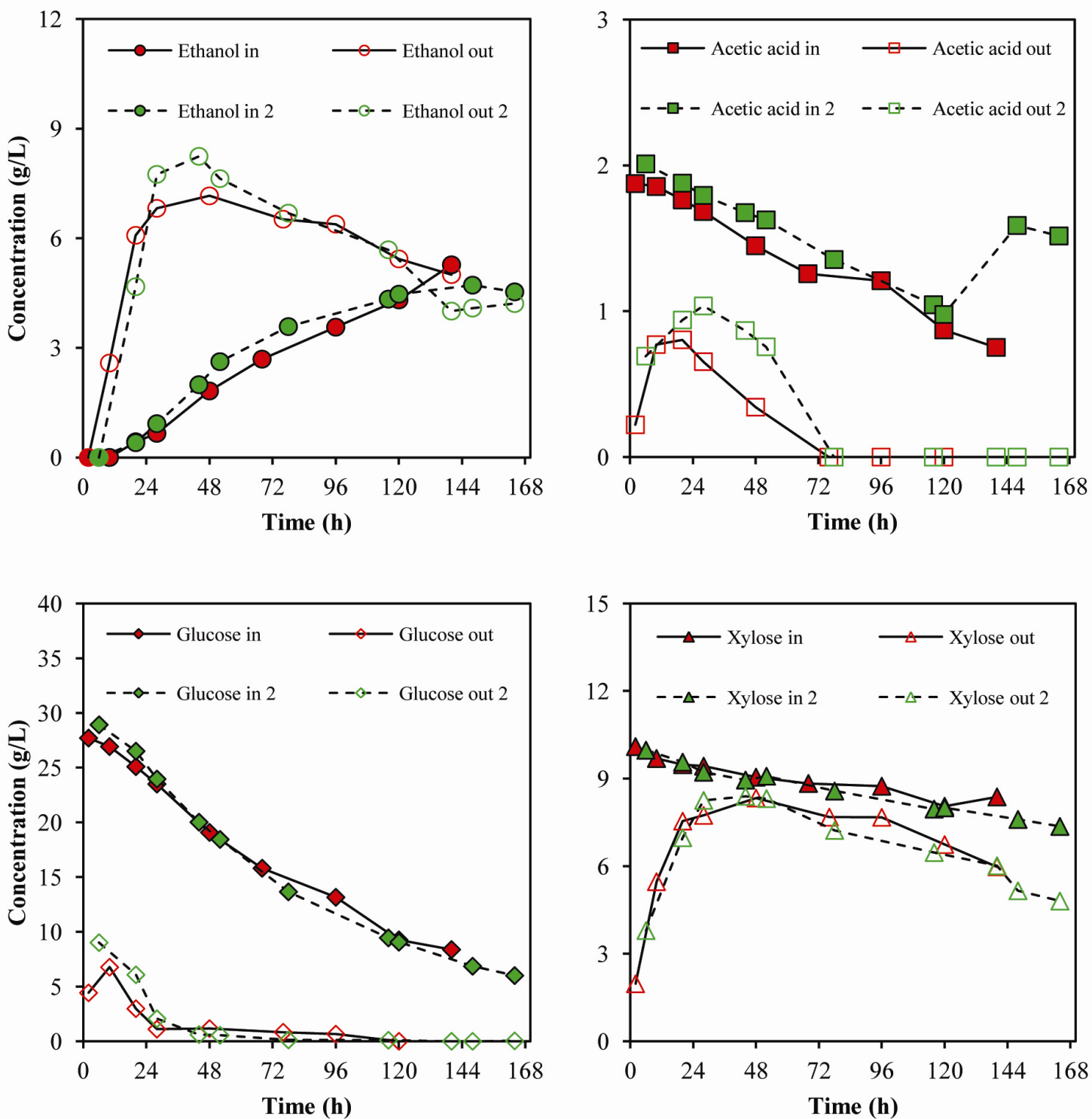

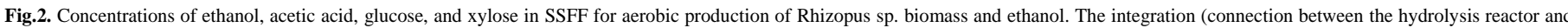

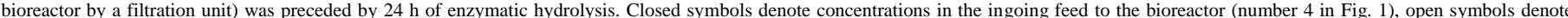

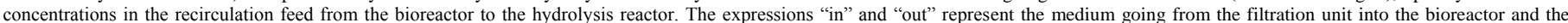
medium that leaves the bioreactor to the hydrolysis reactor, respectively, whereas " 2 " stands for the replicate 2 of the experiment.

The specific growth rate, $\mu(/ \mathrm{h})$, was calculated according to the following equation (Eq. 1):

$$
\mu=\frac{\ln \left(\frac{x}{x_{0}}\right)}{\mathrm{t}}
$$

Where $x_{0}$ denotes the initial biomass concentration and $\mathrm{x}$ is the biomass concentration after the elapsed time $t$. Assuming a constant $\mu$ is debatable because of the dynamic conditions such as substrate concentrations and the fact that the results are sensitive to the accuracy of wet weight measurements of the initial biomass. Growth in the form of pellets is also known to be different from that of free cells (Metz and Kossen, 1977), but considering the small size of the used pellets, this effect can be assumed to be relatively low. However, the results tabulated in Table 1 show that $\mu$ as measured, hardly changed corresponding to the substrate composition, i.e., $0.013 / \mathrm{h}<\mu<$ $0.015 / \mathrm{h}$ under aerobic conditions. It could be concluded that the growth rate showed no tendency to be affected by glucose concentrations as long as alternative carbon sources such as acetic acid, ethanol, and xylose were present. However, more efficient aeration could have resulted in a higher growth rate.

The biomass yields reported in Table 1 ranged between 0.24 and 0.34 $\mathrm{g} / \mathrm{g}$ consumed monomeric sugars (arabinose, galactose, glucose, and xylose), acetic acid, and ethanol, except for the case with enzymatic hydrolysis (i.e., high initial glucose concentration, Fig. 2) where the biomass yield dropped due to ethanol production. These biomass yields were in harmony with the yield obtained in separate batch experiments with synthetic medium containing individual carbon sources $(10 \mathrm{~g} / \mathrm{L}$ of each compound except for acetic acid; $5 \mathrm{~g} / \mathrm{L}$ ). The measured yields of biomass for acetic acid, ethanol, and xylose in these trials were $0.30 \mathrm{~g} / \mathrm{g}$, $0.30 \mathrm{~g} / \mathrm{g}$, and $0.29 \mathrm{~g} / \mathrm{g}$, respectively, after $140 \mathrm{~h}$ batch cultivation $(96 \mathrm{~h}$ for acetic acid, data not shown). The corresponding consumption of glucose was faster (less than $42 \mathrm{~h}$ ), but the resulting biomass yield was as low as 
Table 1.

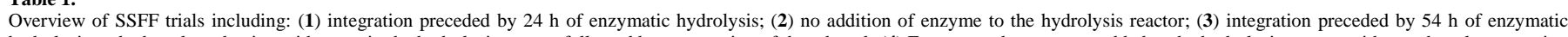
hydrolysis and ethanol production with yeast in the hydrolysis reactor followed by evaporation of the ethanol; (4) Enzyme and yeast were added to the hydrolysis reactor with no ethanol evaporation before integration; (5) The air supply to the bioreactor was switched off at $\mathrm{t}=72 \mathrm{~h}$ with concomitant addition of enzymes to the hydrolysis reactor. The glucose column refers to the concentration of glucose in the bioreactor and how it developed (the uptake of arabinose and galactose are not reported).

\begin{tabular}{|c|c|c|c|c|c|c|c|c|c|}
\hline \multirow{2}{*}{ SSFF trial } & \multirow{2}{*}{$\begin{array}{l}\text { Glucose } \\
\text { (g/L) }\end{array}$} & \multirow{2}{*}{$\begin{array}{c}\text { Cultivation time } \\
\text { (h) }\end{array}$} & \multirow{2}{*}{$\begin{array}{l}\mathbf{Y}_{\mathrm{X} / \mathrm{S}} \\
(\mathrm{g} / \mathrm{g})\end{array}$} & \multirow{2}{*}{$\begin{array}{l}\mathbf{Y}_{\mathrm{E} / \mathrm{S}} \\
(\mathrm{g} / \mathrm{g})\end{array}$} & \multirow{2}{*}{$\underset{(/ \mathbf{h})}{\mu}$} & \multicolumn{4}{|c|}{ Distribution of uptake (\%) } \\
\hline & & & & & & Glucose & Xylose & Ethanol & Acetic acid \\
\hline \multirow[b]{2}{*}{ (1) Enzyme addition } & \multirow[b]{2}{*}{$\sim 27$ decreases to $\sim 6$} & 140 & $0.11^{\mathrm{a}}$ & $0.21^{\mathrm{a}}$ & 0.013 & 86 & 9 & - & 6 \\
\hline & & 168 & $0.14^{\mathrm{a}}$ & $0.14^{\mathrm{a}}$ & 0.014 & 80 & 12 & - & 7 \\
\hline (2) No enzyme addition & 2.2 decreases to 0.2 & 72 & $0.32^{\mathrm{a}}$ & - & 0.015 & 46 & 43 & - & 12 \\
\hline (3) SSF \& evaporation ${ }^{\text {b }}$ & 2.2 to ND & 96 & $0.34^{\mathrm{a}}$ & $0.10^{\mathrm{a}}$ & 0.015 & 28 & 39 & - & 25 \\
\hline \multirow{2}{*}{ (4) Yeast in hydrolysis ${ }^{c}$} & \multirow{2}{*}{$<0.3$} & 96 & $0.24^{\mathrm{a}}$ & \multirow{2}{*}{ Cons. } & 0.015 & $<1$ & 53 & 22 & 25 \\
\hline & & 120 & $0.30^{\mathrm{a}}$ & & 0.013 & 1 & 37 & 28 & 34 \\
\hline $\begin{array}{l}\text { (5) Anaerobic with } \\
\text { enzyme addition }\end{array}$ & peaks at 17.5 & 94 & $0.034^{\mathrm{d}}$ & $0.40^{\mathrm{d}}$ & 0.002 & 95 & 5 & - & $<1$ \\
\hline
\end{tabular}

$\mathrm{Y}_{\mathrm{X} / \mathrm{S}}=$ yield ( $\mathrm{g}$ of fungal biomass/g of consumed carbon source) $\quad \mathrm{Y}_{\mathrm{E} / \mathrm{S}}=$ yield $(\mathrm{g}$ of ethanol/g of consumed carbon source)

"Cons." = consumed

"ND" = not detected

${ }^{a}$ Biomass and ethanol yields related to consumed amounts of acetic acid, arabinose, ethanol, glucose, galactose, and xylose.

${ }^{\mathrm{b}}$ This treatment resulted in reduced amounts of glucose and ethanol prior to SSFF integration.

${ }^{c}$ This method sharply reduced the glucose content in the flux into the bioreactor.

${ }^{\mathrm{d}}$ Biomass and ethanol yields related to consumed amounts of glucose and xylose.

$0.11 \mathrm{~g} / \mathrm{g}$ due to formation of ethanol and glycerol (data not shown), confirming overflow metabolism (Crabtree effect) for Rhizopus sp. (Millati et al., 2005; Lennartsson et al., 2009). The pooled standard deviation for the biomass yields was 0.042 ( $\pm 1 \mathrm{SD})$.

\subsection{Steering the uptake of carbon sources}

In a separate experiment with synthetic medium, the uptake pattern was studied in a cultivation, where acetic acid, ethanol, glucose, lactic acid, and xylose were added to the same cultivation of Rhizopus sp. in aerobic shakeflasks. The results showed a relatively rapid consumption of glucose, followed by acetic acid, whereas xylose and ethanol with similar consumption trends were not totally consumed after $72 \mathrm{~h}$ of cultivation (Fig. 3). Lactic acid frequently occurs as an undesired metabolite produced by contaminants
(Skinner and Leathers, 2004) and its uptake by other zygomycetes is documented (Ferreira et al., 2013). However, no measurable consumption of lactic acid by the Rhizopus sp. strain was confirmed in this experiment. It is observed that the preference of carbon source, among those examined, under the examined conditions can be ranked as follows: glucose $>$ acetic acid $>$ xylose \& ethanol (Fig. 3). The measured specific growth rate, $\mu$, was $0.013 / \mathrm{h}$, i.e., similar to the level in the SSFF experiments with wheat straw hydrolysate (Table 1), but it is difficult to differentiate the effects of inhibitors and different aeration rates.

In the SSFF experiment with cellulase addition, it is clearly visible that the glucose uptake was relatively efficient but had no visible positive effects on the specific growth rate. Instead, ethanol was produced in a respire-fermentative pattern (Fig. 2 and Table 1). In a biorefinery context, it is probable that glucose, if available, would be used for other

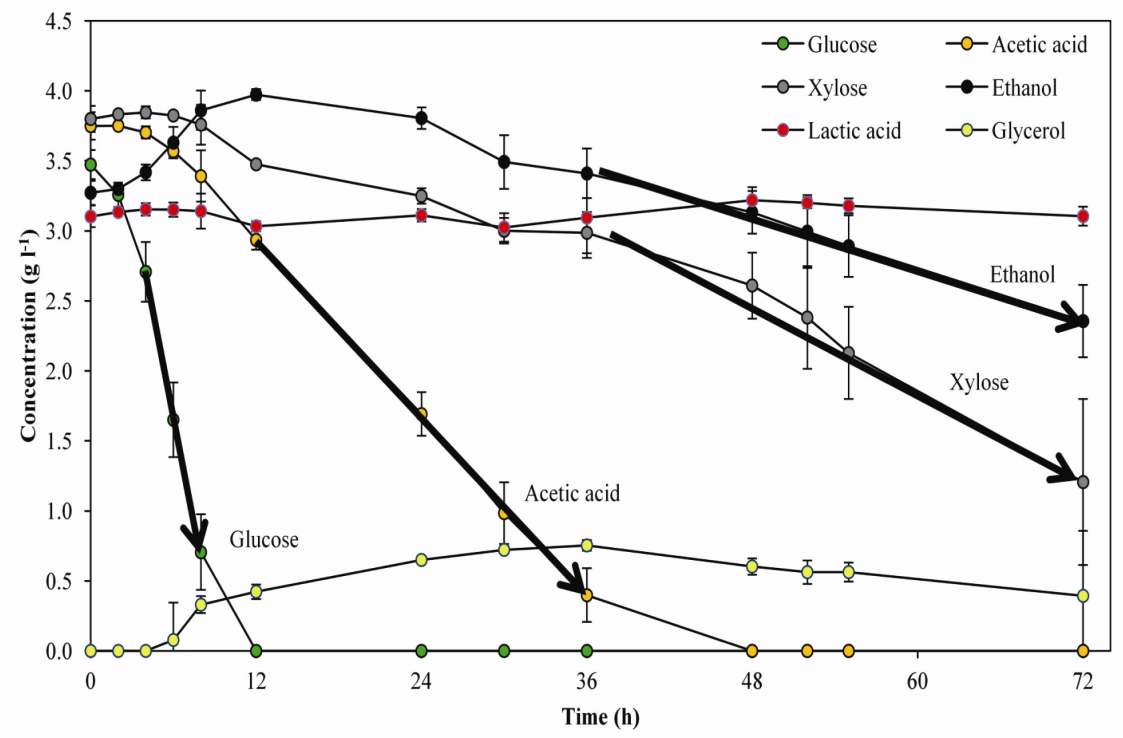

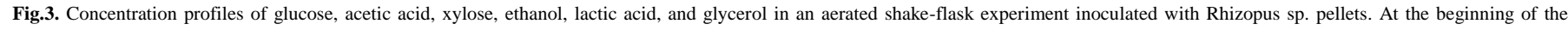
cultivation, the concentration of all mixed components except glycerol, which was produced during cultivation, was $3.5 \mathrm{~g} / \mathrm{L}$. Error bars denote $\pm 1 \mathrm{SD}$. 

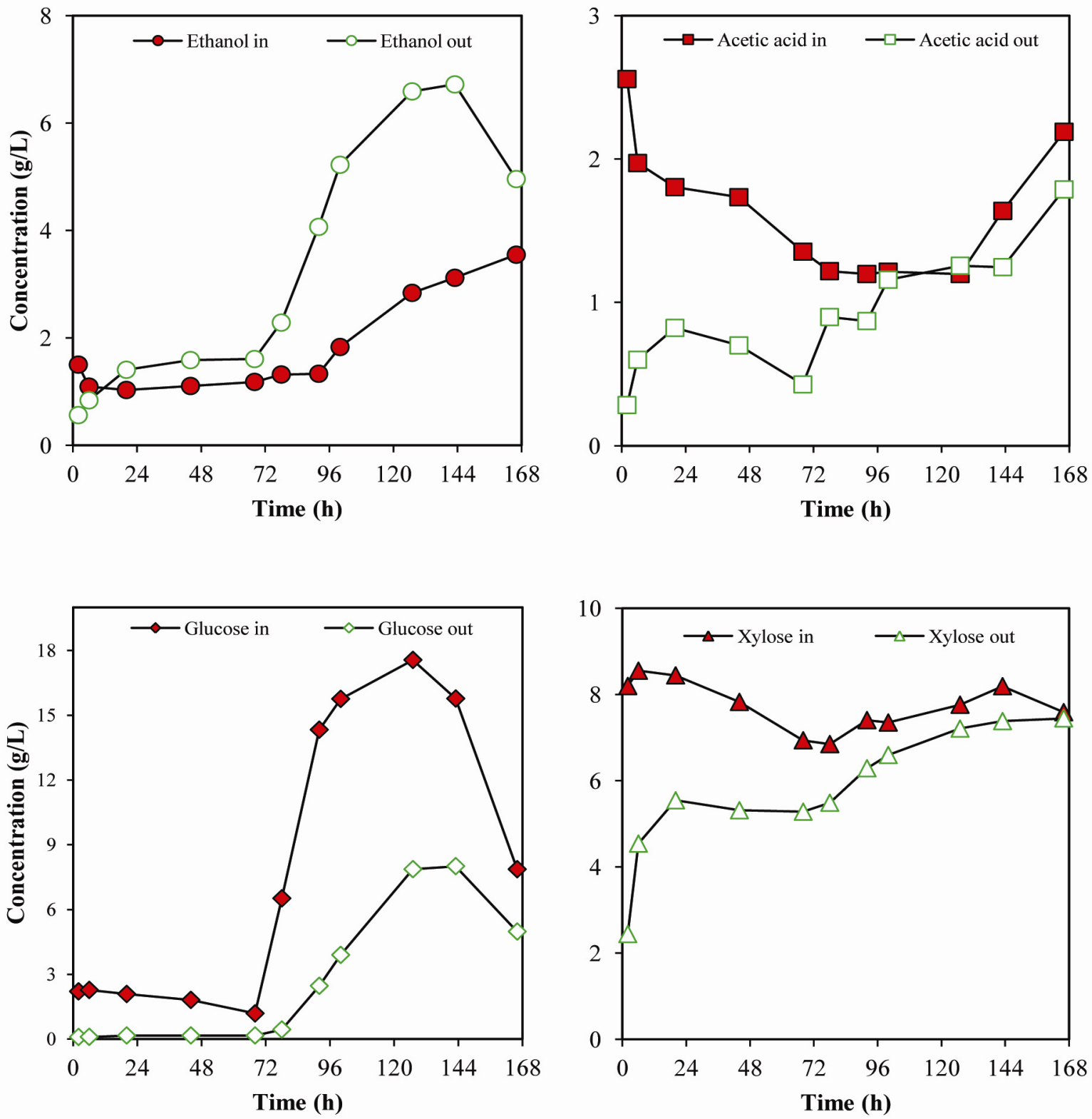

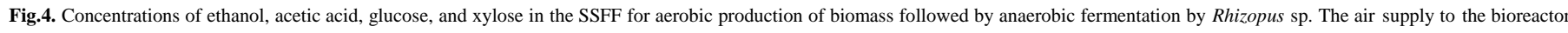

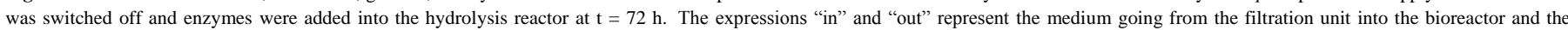
medium that leaves the bioreactor to the hydrolysis reactor, respectively.

purposes, such as ethanol production by fermentation. Therefore, it may be advantageous to utilize other compounds than glucose for biomass formation. By excluding the enzymatic decomposition, the glucose concentration was sharply reduced, resulting in a higher uptake of xylose and acetic acid. Combining the cultivation of Rhizopus sp. by SSFF with the addition of $S$. cerevisiae in the hydrolysis reactor further reduced the glucose concentration in the feed and increased the consumption of xylose, acetic acid, and ethanol. The use of enzymatic hydrolysis and fermentation followed by distillation prior to SSFF cultivation produced a result remarkably similar to the case with the untreated slurry, i.e., without enzyme addition (Table 1).

In conclusion, reducing the glucose concentration in the present study steered the uptake by Rhizopus sp. to xylose and acetic acid, which both can be present as residual compounds in a biorefinery, without reducing either the biomass yield or the specific growth rate.

\subsection{Fermentation by Rhizopus sp.}

Rhizopus sp. is also useful as a fermenting organism for ethanol production and the combined production of valuable biomass and ethanol is interesting in a biorefinery perspective. Performing a complete list of process possibilities is beyond the scope of this study, and only the production of ethanol and animal feed using Rhizopus sp. as producing organism was investigated herein.

Two experiments were carried out, where Rhizopus sp. was initially grown aerobically on straw hydrolysate in order to build up biomass. One of the trials was stopped after $72 \mathrm{~h}$ (referred to in Table 1 as cultivation without enzyme addition), and the biomass was harvested and measured $(4.4 \mathrm{~g})$. The second experiment was initiated in a similar way, but after 72 $\mathrm{h}$, cellulase (10 FPU/g SS) was added and the air supply to the fermentation reactor was switched off (Fig. 4). 
During the subsequent $94 \mathrm{~h}$, the amount of biomass increased to $6.4 \mathrm{~g}$, suggesting a specific growth rate $(\mu)$ of $0.034 / \mathrm{h}$ during the anaerobic phase (Table 1).

In the time span from 72 to $166 \mathrm{~h}$, at least $11.5 \mathrm{~g}$ of ethanol was produced (some may have evaporated), which would suggest an ethanol yield of 0.40 $\mathrm{g} / \mathrm{g}$ consumed glucose and xylose, and an ethanol productivity of $0.023 \mathrm{~g} / \mathrm{g} / \mathrm{h}$, based on the average biomass concentration. The volumetric productivity of ethanol, $0.24 \mathrm{~g} / \mathrm{L} / \mathrm{h}$, was relatively low if compared with optimized fermentations with S. cerevisiae (Balat, 2011). The xylose uptake corresponded to only $5 \%$ of the consumed carbon source and the uptake should be a sign of leakage of oxygen into the fermentation vessel, considering that fungi normally do not consume xylose under anaerobic conditions. According to the measurements, the concentration of xylose in the hydrolysis vessel increased after $72 \mathrm{~h}$, indicating the release of xylose from the solid fraction as a result of the enzymatic decomposition.

\subsection{Impact of inhibitors}

After dilution to $5.0 \% \mathrm{SS}$, the concentrations of acetic acid, furfural, and HMF were $1.8 \mathrm{~g} / \mathrm{L}, 0.65 \mathrm{~g} / \mathrm{L}$, and $1.3 \mathrm{~g} / \mathrm{L}$, respectively. Considering a previous study (FazeliNejad et al., 2013), these levels should not be very inhibiting by themselves. It is worth quoting that hydrolysates of lignocellulosic material usually contain other inhibitors as well, such as phenolic compounds, whose concentrations were not measured in the present study. It was observed in all the SSFF trials that ingoing furfural and HMF were completely converted (i.e., not detected in the outflow) after 6-8 h of the integrated fermentation, confirming in situ conversion of these compounds by Rhizopus sp. (FazeliNejad et al., 2013). Furthermore, the specific growth rate, $\mu$, was similar in the hydrolysate-based SSFF experiments and the shake-flask experiments with synthetic medium. It could thus be assumed that the impact of inhibitors was limited.

\section{Conclusions}

Rhizopus sp. in pellet form was successfully used for aerobic production of biomass (animal feed) by SSFF from acid-pretreated wheat straw slurry with biomass yields of up to $0.34 \mathrm{~g}$ biomass/g consumed monomeric sugars and acetic acid. A surplus of glucose in the feed resulted in ethanol production and reduced the biomass yield, whereas limiting glucose concentrations resulted in higher consumption of xylose and acetic acid. The specific growth rate was in the range of $0.013 / \mathrm{h}$ and $0.015 / \mathrm{h}$ and did not appear to be influenced by the composition of the carbon source. Under anaerobic conditions, an ethanol yield of $0.40 \mathrm{~g} / \mathrm{g}$ and an ethanol productivity of 0.023 $\mathrm{g} / \mathrm{g} / \mathrm{h}$ were obtained using the Rhizopus sp. pellets. Overall, the present strategy benefits from the easier separation of the biomass from the medium and the fungus ability to assimilate carbon residuals in comparison with when yeast is used. More specifically, it allows in situ separation of insoluble solids and hence, a two-stage cultivation system practiced for production of biomass and ethanol from whole stillage is not needed to be applied if biomass is desired as a separate value-added product.

\section{Acknowledgement}

This work was financially supported by the Swedish Energy Agency.

\section{References}

[1] Adney, B., Baker, J., 2008. Measurement of cellulase activities. National Renewable Energy Laboratory.

[2] Baboukani, B.S., Vossoughi, M., Alemzadeh, I., 2012. Optimisation of dilute-acid pretreatment conditions for enhancement sugar recovery and enzymatic hydrolysis of wheat straw. Biosys. Eng. 111, 166-174.

[3] Balat, M., 2011. Production of bioethanol from lignocellulosic materials via the biochemical pathway: A review. Energy Convers. Manage. 52, 858-875.

[4] Canilha, L., Carvalho, W., Batista, J., e Silva, A., 2006. Xylitol bioproduction from wheat straw: hemicellulose hydrolysis and hydrolyzate fermentation. J. Sci. Food Agr. 86, 1371-1376.
[5] Cherubini, F., 2010. The biorefinery concept: Using biomass instead of oil for producing energy and chemicals. Energy Convers. Manage. 51, 1412-1421.

[6] FazeliNejad, S., Brandberg, T., Lennartsson, P.R., Taherzadeh, M. J., 2013. Inhibitor Tolerance: A Comparison between Rhizopus sp and Saccharomyces cerevisiae. Bioresources. 8, 5524-5535.

[7] Ferreira, J.A., Lennartsson, P.R., Edebo, L., Taherzadeh, M.J., 2013 Zygomycetes-based biorefinery: Present status and future prospects. Bioresour. Technol. 135, 523-532.

[8] Gnansounou, E., Dauriat, A., 2010. Techno-economic analysis of lignocellulosic ethanol: A review. Bioresour. Technol. 101, 49804991.

[9] Ishola, M.M., 2014. Novel application of membrane bioreactors in lignocellulosic ethanol production, $\mathrm{PhD}$, University of Borås, Borås, Sweden.

[10] Ishola, M.M., Jahandideh, A., Haidarian, B., Brandberg, T., Taherzadeh, M.J., 2013. Simultaneous saccharification, filtration and fermentation (SSFF): A novel method for bioethanol production from lignocellulosic biomass. Bioresour. Technol. 133, 68-73.

[11] Kim, Y., Mosier, N. S., Hendrickson, R., Ezeji, T., Blaschek, H. Dien, B., Cotta, M., Dale, B., Ladisch, M.R., 2008. Composition of corn dry-grind ethanol by-products: DDGS, wet cake, and thin stillage. Bioresour. Technol. 99, 5165-5176.

[12] Lennartsson, P.R., Karimi, K., Edebo, L., Taherzadeh, M.J., 2009 Effects of different growth forms of Mucor indicus on cultivation on dilute-acid lignocellulosic hydrolyzate, inhibitor tolerance, and cell wall composition. J. Biotechnol. 143, 255-261.

[13] Leonard, R.H., Hajny, G.J., 1945. Fermentation of wood sugars to ethyl alcohol. Ind. Eng. Chem. 37, 390-395.

[14] Metz, B., Kossen, N.W.F., 1977. The growth of molds in the form of pellets - a literature review. Biotechnol. Bioeng. 19, 781-799.

[15] Millati, R., Edebo, L., Taherzadeh, M.J., 2005. Performance of Rhizopus, Rhizomucor, and Mucor in ethanol production from glucose, xylose, and wood hydrolyzates. Enzyme Microb. Technol. 36, 294-300

[16] Nyman, J., Lacintra, M.G., Westman, J.O., Berglin, M., Lundin, M. Lennartsson, P.R., Taherzadeh, M.J., 2013. Pellet formation of zygomycetes and immobilization of yeast. New Biotechnol. 30, 516522.

[17] Olofsson, K., Bertilsson, M., Lidén, G., 2008. A short review on SSF-an interesting process option for ethanol production from lignocellulosic feedstocks. Biotechnol. Biofuels. 1, 1-14.

[18] Pandey, A., Höfer, R., Larroche, C., Taherzadeh, M.J., Nampoothiri, M., 2015. Industrial Biorefineries and White Biotechnology. Elsevier.

[19] Peng, F., Peng, P., Xu, F., Sun, R.C., 2012. Fractional purification and bioconversion of hemicelluloses. Biotechnol. Adv. 30, 879-903.

[20] RFA, 2014. Ethanol industry outlook. Renewable Fuels Association.

[21] Skinner, K., Leathers, T., 2004. Bacterial contaminants of fuel ethanol production. J. Ind. Microbiol. Biot. 31, 401-408.

[22] Sluiter, A., Hames, B., Ruiz, R., Scarlata, C., Sluiter, J., Templeton, D., Crocker, D., 2011. Determination of structural carbohydrates and lignin in biomass. National Renewable Energy Laboratory, Colorado, USA.

[23] Talebnia, F., Karakashev, D., Angelidaki, I., 2010. Production of bioethanol from wheat straw: An overview on pretreatment, hydrolysis and fermentation. Bioresour. Technol. 101, 4744-4753.

[24] Wheals, A.E., Basso, L.C., Alves, D.M.G., Amorim, H.V., 1999 Fuel ethanol after 25 years. Trends Biotechnol. 17, 482-487.

[25] Wikandari, R., Millati, R., Lennartsson, P.R., Harmayani, E. Taherzadeh, M.J., 2012. Isolation and characterization of Zygomycetes fungi from tempe for ethanol production and biomass applications. Appl. Biochem. Biotechnol. 167, 1501-1512.

[26] Wingren, A., Galbe, M., Zacchi, G., 2003. Techno-economic evaluation of producing ethanol from softwood: Comparison of SSF and SHF and identification of bottlenecks. Biotechnol. Progr. 19, 1109-1117. 